\title{
A ANTROPOLOGIA PRAGMÁTICA COMO UMA DOUTRINA DA PRUDÊNCIA NAS VERSÓES DOS CURSOS DE ANTROPOLOGIA DE KANT
}

\author{
Jorge Vanderlei Costa da Conceição ${ }^{1}$
}

Resumo: O objetivo deste artigo é evidenciar que a ideia de antropologia pragmática desenvolvida nas versóes dos cursos de antropologia, que são Collegentwürfe, Menschenkunde e Anthropologie DohnaWundlackende, se ocupa de uma definição moral, porque ela está subordinada à doutrina da prudência. Essa é compreendida como a capacidade de os seres humanos influenciarem uns aos outros, segundo certos fins, os quais deverão ser úteis na vida em sociedade. Além disso, delimita-se que o sentido do adjetivo "pragmático", presente nessas versóes dos cursos de antropologia, foi retirado da obra Initia Philosophiae practicae prima, de Baumgarten, pois, nas anotaçóes de Kant acerca dessa obra, os motivos pragmáticos sempre determinarão leis privadas do arbítrio, as quais poderão, a priori, representar um interesse moral e, a posteriori, a realização de um fim almejado pelo ser racional finito. Por essa razáo, defende-se haver nas obras kantianas citadas uma sinonímia entre a noção de antropologia pragmática e de doutrina da prudência.

Palavras-chave: Antropologia pragmática. Doutrina da prudência. Moral aplicada. Ética impura. Baumgarten.

\section{INTRODUÇÃo}

O objetivo deste artigo é mostrar que a noção de antropologia pragmática desenvolvida nas anotaçôes dos cursos de antropologia kantiana, Collegentwürfe, Menschenkunde e Die philosophischen Hauptvorlesungen Immanuel Kants: nach den neu aufgefundenen Kollegheften des Grafen Heinrich zu Dohna-Wundlacken ${ }^{2}$, trata de uma definição moral. Isso é importante, uma

1 Professor pesquisador em estágio de pós-doutoramento na Universidade Estadual de Campinas (Unicamp), Campinas, SP - Brasil. (D) https://orcid.org/0000-0002-7923-4752 E-mail: anedotismo@ yahoo.com.br.

${ }^{2}$ As obras de Kant serão citadas de acordo com as siglas estabelecidas internacionalmente pela direção da Revista Kant-Studien e adotadas pela Kant-Gesellschaft e pela a Sociedade Kant Brasileira. Ver http://www.degruyter.com/files/down/instructions/ksins_e.pdf. O texto citado em alemão na nota de

http://doi.org/10.1590/0101-3173.2020.v43n2.05.p77

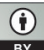

This is an open-access article distributed under the terms of the Creative Commons Attribution License. 
vez que, por exemplo, Louden (2011) sustenta que a definição de antropologia pragmática abordada na obra Antropologia de um ponto de vista pragmático pode ser reduzida à antropologia moral aplicada. Em contrapartida, Perez (2009) também defende que a antropologia pragmática está inclusa na razão prática, mas isso não significa que ela está restrita à segunda parte da metafísica dos costumes, como indica Louden. Em vez disso, Perez argumenta que o problema central da antropologia pragmática, tal como a encontramos na Antropologia de um ponto de vista pragmático, é demonstrar a validade do seguinte juízo: o homem é cidadão do mundo.

Perez (2009) considera que essa proposição é sintética e, a priori, prática; se aceitarmos essa tese, então não poderemos meramente afirmar que a antropologia pragmática está inclusa na parte impura da metafísica dos costumes. Para resolver a questão aqui indicada, demonstraremos que a definição de antropologia pragmática presente nas três versóes dos cursos de antropologia já citadas trata de uma definição moral. É importante observar que nos limitaremos, neste trabalho, à análise desse conceito nas três versóes dos cursos de antropologia indicados, porque visamos a evidenciar que, nessas versóes dos cursos de antropologia, a ideia de antropologia moral pertence à razão prática.

A primeira versão analisada dos cursos de antropologia é a de Collegentwürfe; Kant ministrou esses cursos de 1770 até 1790, e essa obra é dividida entre as aulas de 1770 até 1780 e de 1780 até 1790 . Nessas anotações, Kant definiu pela primeira vez a antropologia pragmática como a investigação do que homem é capaz de fazer de si mesmo como um ser livre. Essa definição de antropologia pragmática fora escrita aproximadamente 25 anos antes da publicação da Antropologia de um ponto de vista pragmático. Além disso, trechos dessas aulas são contemporâneos à carta de Kant enviada a Herz $(B r$, AA, 10:144-146), correspondência na qual Kant manifestou a sua intenção em transformar os seus cursos de antropologia em uma disciplina acadêmica, o que nunca aconteceu. Essa informação é importante, pois ela nos ajudará a perceber o que Kant compreendida por antropologia, nessa época.

Nessa correspondência, Kant afirma o seguinte:

rodapé será reproduzido conforme está no texto original, sem as correçôes do acordo ortográfico de 1996 e também se reproduzirá o texto com os possíveis erros ortográficos e de concordância presentes no texto kantiano. 
Li a resenha crítica da antropologia de Platner. Náo tinha os resultados de um crítico para apresentar agora, mas alegro-me de ver isso desenvolvido no progresso de suas habilidades. Pela segunda vez neste inverno ensino antropologia no Kollegium privatum e pretendo organizar esses cursos em uma disciplina acadêmica. [...] Tenho o propósito de expor, por meio desses cursos, ao menos as fontes de todas as ciências que debatem os costumes, a destreza e o convívio social e, consequentemente, fundar o domínio prático. Por isso, procuro mais os fenômenos e as suas leis do que as primeiras causas da possibilidade da modificação da natureza humana em geral. Por conseguinte, não se utiliza mais as sutis e aos meus olhos totalmente inúteis investigaçóes acerca do modo como os órgáos do corpo se relacionam com os pensamentos. [...] Em períodos intermediários, trabalho para fazer isso, em minha opiniấo, observaçóes agradáveis, um exercício preliminar de habilidade, de prudência e até de sabedoria para os jovens acadêmicos, na medida em que se diferencia a geografia física das outras instruçóes, que podem ser chamadas de conhecimento do mundo $(B r, \mathrm{AA}, 10: 144-146)^{3}$.

De acordo com os planos de Kant, os cursos de antropologia são concebidos como parte das ciências práticas e como instruções preliminares do conhecimento do mundo, mas o viés prático lhe permite diferenciar essas aulas introdutórias das de geografia física. Por essa razão, nessa correspondência, ele também esclarece que a sua antropologia não é uma investigação fisiológica e nem psicológica, como defendia Platner, Anthropologie für Arzte und Weltweise, mas sim a investigação do que o homem é capaz de fazer de si mesmo como um ser livre.

Em Colleg, Kant define a sua investigação de antropologia da seguinte maneira: "não investigamos aqui o homem pelo o que ele é de modo natural, mas para saber - o que ele pode fazer de si mesmo e como se pode ter proveito disso" (Colleg, $A A, 15: 559-560)^{4}$. Adickes organizou as reflexóes sobre antropologia de Kant e, segundo essa organização, o trecho supracitado provavelmente

${ }^{3}$ Allein mein Plan ist ganz anders. Die Absicht die ich habe ist durch dieselbe die Quellen aller Wissenschaften die der Sitten der Geschicklichkeit des Umganges der Methode Menschen zu bilden u. zu regieren mithin alles Praktischen zu eröffnen. Da suche ich als denn mehr Phänomena u. ihre Gesetze als die erste Gründe der Möglichkeit der Modifikation der menschlichen Natur überhaupt. Daher die subtile u. in meinen Augen auf ewig vergebliche Untersuchung über die Art wie die Organe des Körper mit den Gedanken in Verbindung stehen ganz wegfällt. [...] Ich arbeite in Zwischenzeiten daran, aus dieser in meinen Augen sehr angenehmen Beobachtungslehre eine Vorübung der Geschicklichkeit der Klugheit und selbst der Weisheit vor die akademische Jugend zu machen welche nebst der physischen Geographie von aller andern Unterweisung unterschieden ist und die Kenntnis der Welt heißen kann. ${ }^{4}\left({ }^{5}\right.$ Wir untersuchen hier den Menschen nicht nach dem, was er natürlicher Weise ist, sondern um zu wissen - was er aus sich machen und wie man ihn brauchen kann. 
fora escrito entre 1773-1775. Isso sugere que esse trecho é contemporâneo à carta enviada a Markus Herz, em 1773, na qual Kant manifesta a sua intenção em transformar os seus cursos de antropologia em uma disciplina acadêmica. Porquanto, em Colleg, o adjetivo pragmático indica "o conhecimento, do qual o uso geral em sociedade é viável - especulativo. Prudência do mundo [Weltklugheit], Sabedoria [Weltweisheit]" (Colleg, AA, 15:661) $)^{5}$.

É importante destacar que a antropologia, em Colleg, é definida como a investigação do uso [Gebrauch] que o homem faz do seu conhecimento no mundo. Nesse sentido, o conceito de pragmática, entendido como o proveito que o homem faz do seu conhecimento no mundo, não deve ser tomado como uma mera oposição ao conhecimento especulativo. Em outras palavras, a antropologia pragmática é a investigação dos diferentes usos que o homem faz do seu entendimento no mundo; nesse momento da produção kantiana, trata do domínio teórico e prático da razão. Por esse motivo, o adjetivo pragmático enfatiza o proveito que o homem pode ter, ao aplicar as suas faculdades cognitivas no mundo e, por isso, não se refere ao processo de justificação dessas operaçóes judicativas. Dito isso, nas palavras de Kant (Colleg, AA, 15:659), “[...] ainda não se tem nenhuma antropologia pragmática. $\mathrm{O}$ uso por isso em todos os atos da vida. Fontes. Histórias (Romance. E em todo exagero das peças de teatro)" .

A antropologia pragmática é definida através do uso que o homem faz das suas faculdades cognitivas, em diferentes atos da vida, ou seja, em diferentes domínios de aplicação de proposiçôes. Para demarcar a sua metodologia investigativa, Kant (Colleg, AA, 15:659) argumenta o seguinte:

[...] conhecimento do mundo é conhecimento do homem. "Ele possui o mundo [er hat Welt]" quer dizer: ele é treinado e instruído através da etiqueta [Hofmanier ${ }^{7}$. A cabeça vazia contra a pedante. Para conhecer o mundo [um die Welt zu kennen], o homem não precisa viajar, de casa ele observa e estuda sobre isso. Conhecimento local e conhecimento geral. Aquele é estrito e sem utilização racional. Observação da vida comum. Das histórias e das biografias. Este tipo de doutrina é. 1. o habilidoso. 2. o

\footnotetext{
$5 \mathrm{~g}$ Pragmatisch ist die Erkenntnis, von der sich ein allgemeiner Gebrauch in der Gesellschaft machen lässt. — spekulativ. Weltklugheit, Weltweisheit. (Collegentwürfe 15:661)

${ }^{6}$ Man hat noch keine pragmatische Anthropologie. Gebrauch davon in allen Handlungen des Lebens. Quellen. Geschichte (Romanen. und Schauspiele übertreiben alles).

${ }^{7} \mathrm{O}$ termo Hofmanier é derivado do termo Hof, que, nesse caso, significa corte. Em alemão, Hofmanier significa o modo como os nobres se vestiam e se comportavam nas cortes. Dito isso, optamos por traduzir Hofmanier por etiqueta, pois esse termo indicava o conjunto de cerimônias utilizadas pela nobreza na corte.
} 
prudente. 3. o sábio: conhecimento escolástico, conhecimento pragmático e conhecimento moral (o primeiro conhecimento instrui o segundo civiliza e o terceiro moraliza). A prudência conduz à sociedade, na qual estamos como seres humanos. Todas as outras ciências pragmáticas se apropriam disso. História pragmática ${ }^{8}$.

Para Kant, o conhecimento do mundo é formado pelas instruçóes de Geografia física e de Antropologia (Anth, AA, 7:119/ PG, AA, 9:157); a primeira investiga o homem enquanto habitante da terra e a segundo o homem enquanto um cidadão cosmopolita. É importante ressaltar que, nessa anotação dos cursos de antropologia, o conceito de conhecimento do homem é sinônimo de antropologia pragmática e o de conhecimento do mundo é o de geografia física (CONCEIÇÃO, 2017). Quanto à definição de antropologia, no Colleg, ela se faz a partir da oposição entre o conhecimento pragmático e o conhecimento escolástico, chamado por Kant de conhecimento pedante.

No caso do conhecimento do mundo como uma doutrina popular, o homem não é apenas instruído, isto é, treinado para utilizar o seu entendimento segundo as regras especulativas ou de etiqueta, porém, ele investiga a si mesmo e o mundo como um domínio de aplicabilidade do seu conhecimento. Por essa razáo, o objetivo dos cursos de antropologia kantianos não é meramente instruir o homem, ao invés disso, ele visa a auxiliar o homem no seu processo educacional, civilizatório e moralizador. Assim, as biografias e as histórias compóem o conhecimento antropológico como meios auxiliares, porque elas fornecem ao antropólogo uma visão de como o ser humano usa as regras de civilidade e de moralização e de que forma ele modifica a sua natureza, ao fazer isso. É importante destacar que os exemplos obtidos através dessas fontes são apenas exemplares, na medida em que a universalidade delas é apenas comparativa.

Foucault (2011) problematiza a noção de antropologia pragmática, nas liçóes de antropologia de Colleg, a partir da ideia de uso, pois, para o pesquisador, a antropologia kantiana investiga o homem por meio do emprego

8 Weltkentnis ist Menschenkentnis. „Er hat welt” heißt: er ist durch Hofmanier dressirt und abgerichtet. Schaler Kopf gegen den pedanten. Um die Welt zu kennen, braucht man eben nicht zu reisen. Man muß zu Hause beobachten und darüber studiren. Localkentnis und Generalkentnis. Jene ist eingeschränkt und ohne Vernünftigen Gebrauch. Beobachtung des gemeinen Lebens. Der Geschichte und biographien. derley Lehren. 1. Die Geschikt. 2. die klug. 3. die weise machen: scholastische, pragmatische und moralische Kentnis. (g einige Erkentnis cultivirt, andre civilisirt, andre moralisirt.) Pragmatische Anthropologie. Klugheit geht auf die Gemeinschaft, darin wir mit Menschen stehen. Alle andere pragmatische Wissenschaften borgen daher. pragmatische Geschichte. 
que ele realiza das suas faculdades cognitivas como um ser mundano e, por essa razáo, Kant teria excluído categoricamente a fisiologia e a psicologia da sua investigação antropológica. De acordo com Foucault (2011, p. 46),

[...] o homem é o jogo da natureza, mas um jogo que ele próprio joga; e se lhe acontece ser jogado, como nas ilusóes dos sentidos, é porque ele próprio jogou-se como vítima deste jogo, ao passo que lhe compete ser dono do jogo, retomá-lo por sua conta no artifício de uma intenção. O jogo tornase então um "künstlicher Spiel [jogo artificial]” e a aparência com que é jogado recebe a sua justificação moral. A Antropologia desenvolve-se, pois, segundo esta dimensáo do exercício humano que vai da ambiguidade do Spiel [jogo] à indecisão da Kunst [arte].

Para delimitar a especificidade da antropologia, Foucault distingue o exame do homem como resultado do jogo da natureza (o que a natureza faz dele?) e como resultado de um jogo artificial (o que o homem é capaz de fazer de si mesmo como um ser livre?). O homem é o jogo da natureza, uma vez que ele é um produto dela, o que é investigado pela história natural (fisiologia e psicologia). Entretanto, o homem também é o jogador desse jogo, desde que ele se torna um domínio de aplicação dos próprios enunciados, por isso, ele é capaz de modificar a sua natureza, ou seja, civilizar-se, moralizar-se e educar-se.

Para Foucault, o jogo antropológico é artificial: na medida em que o ser humano se torna o domínio de aplicaçáo do seu próprio conhecimento, ele delimita as regras do jogo. Nesse caso, a antropologia é um jogo artificial, porque esse jogo se constitui na indagação acerca da possibilidade de se atribuir o predicado cidadáo do mundo ao homem, de acordo com Foucault. O jogo é classificado como artificial, pois náo se trata do que a natureza faz do homem, mas se ocupa do que o ser racional finito é capaz de fazer de si mesmo como um ser livre. Dessa maneira, o homem é investigado como um ser no mundo, pelo emprego das suas capacidades racionais nos diferentes atos ou jogos da vida, mas, nesses jogos, o homem não é meramente um produto da natureza, um espectador, posto que ele pode alterar as regras do jogo de acordo com as suas intençóes e, por isso, o homem torna-se um produto no jogo no qual ele é o próprio jogador.

Segundo Foucault, a antropologia kantiana no Colleg apresenta uma oposição entre Spiel e Kunst, porque o homem é problematizado como o jogador ativo dos diferentes jogos de que ele participa, o que nos autoriza a pensar a espécie humana, não como um produto do jogo no domínio teórico 
(habilidade), no da sociabilidade (prudência) e no da moralização (sabedoria), mas sim como um jogador. Assim, a noção de antropologia pragmática, nas liçôes de Colleg, diz respeito à investigação do homem como um produto da atividade do seu entendimento, porque, ao criar um conjunto de conceitos $a$ priori, o homem cria a si mesmo como um ser no mundo, o que nos permite pensá-lo como um produto dessas operaçóes judicativas. Esse jogo é artificial, porque não é o que natureza faz do homem, mas sim o que ele pode fazer de si mesmo como um ser racional, que é educar-se, moralizar-se e civilizar-se. Por fim, podemos afirmar que a antropologia pragmática, em Colleg, se ocupa do proveito que o homem poderá ter, ao aplicar a sua capacidade racional no mundo, proveito o qual é obtido mediante o processo educacional, civilizatório e moralizador.

O segundo texto analisado é o Immanuel Kant's Menschenkunde, pois ele trata dos cursos ministrados por Kant entre 1781-1782, ano da publicação da Crítica da razão pura. Esse texto foi publicado em 1831 por Johann Adam Bergk, que utilizou o pseudônimo de Friedrich Christian Starke. Em Menschenkunde, Kant classifica o conhecimento antropológico de duas maneiras: a antropologia escolástica, que é fundamentada pelos conhecimentos provenientes da fisiologia, da psicologia e da história natural, e a antropologia pragmática, estruturada a partir dos conhecimentos obtidos do domínio prático da razão, mais especificamente da doutrina da prudência.

Sobre a antropologia como uma doutrina da prudência, Kant (V-Anth/ Mensch 1831. p. 5) argumenta o seguinte, em Menschenkunde:

[...] ela (prudência) é um conhecimento do modo como um homem pode ter influência sobre outro e pode dirigi-lo para o seu propósito. Um conhecimento prático se chama pragmático, desde que ele sirva para realizar o nosso propósito geral. Toda doutrina da sabedoria é moral e toda doutrina da prudência é pragmática. Uma doutrina é pragmática, desde que seja prudente e útil para nós nos assuntos públicos, no qual não há apenas teoria pura, mas no qual a práxis é necessária. ${ }^{9}$

De acordo com a citação, o conhecimento do homem, em sentido pragmático, ocupa-se de como uma pessoa pode influenciar outra em favor de

\footnotetext{
9 Sie ist eine Kenntnis von der Art, wie ein Mensch Einfluss auf den Anderen haben und ihn nach seiner Absicht leiten kann. Eine jede praktische Kenntnis, sofern sie dient, unsere gesamten Absicht zu erfüllen, nennt man pragmatisch. Jede Lehre der Weisheit ist moralisch, und jede der Klugheit pragmatisch. Eine Lehre ist pragmatisch, sofern sie uns klug und in öffentlichen Dingen brauchbar macht, wo wir nicht bloß die Theorie, sondern aus die Praxis nötig haben.
} 
um fim; assim, ambas podem realizar um propósito comum, que, nesse caso, é algo útil para o gênero humano nas questôes públicas. Esse propósito geral é delimitado pela prudência, que trata da unificação de todos os seres racionais finitos, em função de um fim comum, que é a felicidade. Por conseguinte, a influência que um ser humano pode exercer sobre outrem não trata de usá-lo como um meio para a realização de um fim privado, ao invés disso, ocupa-se de como os seres humanos podem influenciar uns aos outros, para a realização de fim comum. Feita essa observação, é importante ainda ressaltar que o adjetivo pragmático se refere àquilo que é útil na vida social, nos assuntos públicos, em desfavor aos interesses privados. Por isso, podemos afirmar que a antropologia, em sentido pragmático, em Menschenkunde, ocupa-se da capacidade de os seres humanos utilizarem uns aos outros em favor de um fim geral, desde que esse fim seja útil para nós, nos assuntos públicos.

Sobre a ideia de antropologia escolástica, Kant (V-Anth/Mensch, 1831. p. 6) enfatiza:

[...] a antropologia escolástica trata das regras gerais e suas causas; logo que nós investigamos a causa das regras, obtemos uma pesquisa escolástica. Nossa antropologia pode ser lida por qualquer pessoa, até mesmos pelas damas no toalhete, como algo recreativa, quando se encontra em todos os lugares regras, fornece-se informaçóes, e pode-se ao menos fornecr um guia de orientação em aparente desordem. ${ }^{10}$

Como dito anteriormente, a antropologia escolástica investiga as regras gerais e as causas do comportamento humano, o que Kant reconhece como válido, pois, ao investigarmos o homem do ponto de vista fisiológico e psicológico, encontramos certa regularidade no seu comportamento. Nesse sentido, a antropologia escolástica é composta pelo conhecimento fisiológico e psicológico, mas, segundo o autor, esse tipo de discurso fica restrito ao meio acadêmico. Isso quer dizer que a antropologia escolástica é restrita apenas às discussóes acadêmicas. Ao contrário da antropologia platneriana, exemplo de uma antropologia escolástica, a antropologia pragmática pode ser lida por qualquer pessoa, por divertimento ou pelo menos como um guia de orientação desorganizado sobre o uso que o homem faz das suas faculdades

\footnotetext{
${ }^{10}$ Die scholastische Anthropologie aber handelt von den allgemeinsten Regeln und deren Ursachen; sobald wir also nach der Ursache der Regeln forschen, kommen wir ins Scholastische. Unsere Anthropologie kann von jedermann, sogar von Damen bei der Toilette, gelesen werden, wie sie unterhaltendes hat, wenn man allenthalben auf Regeln stöbt, die Auskunft geben, und wenn man bei scheinbaren Unordnungen immer einen Leitfaden findet.
} 
cognitivas, uma vez que não investigará a causalidade entre as açóes humanas e as suas possíveis causas, porém, como o homem é capaz de modificar a sua própria natureza, por meio do uso que ele faz das suas faculdades cognitivas no mundo.

Em Menschenkunde, Kant define a antropologia pragmática em contraposição à escolástica, a fim de ressaltar que a sua proposta antropológica não visa a descrever o homem nem do ponto de vista fisiológico e nem do ponto de vista psicológico, mas pragmático. Nas anotaçôes de Colleg, as quais são contemporâneas às de Menschenkunde, Kant assinala que a antropologia pragmática não é psicologia e nem fisiologia, pois ela almeja evidenciar o que homem pode fazer de si mesmo como um ser social (racional e livre). Por causa disso, a antropologia pragmática não procura determinar se o homem possui uma alma, tal como a antropologia escolástica, uma vez que náo investiga a causa das operaçóes mentais e nem o processo de justificação dos enunciados; ao invés disso, ocupa-se do resultado do uso que o homem faz do seu conhecimento do mundo.

Kant (Colleg, AA, 15:800) define a antropologia da seguinte forma:

(Mas, por que o conhecimento do mundo é conhecimento do homem?)

Por conseguinte, o conhecimento do homem poderá ser entendido por si mesmo como conhecimento escolar ou conhecimento do mundo. O último é a antropologia pragmática. A última examina tanto quanto, o que é o homem, a fim de extrair as regras do que ele pode fazer de si mesmo ou precisar de outrem. Não psicologia, tal como é o conhecimento escolar. ${ }^{11}$

É importante observar que, tanto em Menchenkunde quanto nas anotaçóes de Colleg de 1780, a antropologia pragmática é sinônimo de conhecimento do mundo, pois ela visa a investigar o que o homem é capaz de fazer de si mesmo socialmente e, por causa disso, náo se investiga o homem do ponto de vista fisiológico e nem psicológico. Ora, a noção de antropologia pragmática, entre 1780, investiga o que homem pode fazer de si mesmo como um ser livre, porque ele é examinado através do uso que ele realiza das suas

${ }^{11}$ (g Warum aber ist Weltkenntnis Menschenkenntnis?)

Menschenkenntnis also kann selbst entweder als Schulkenntnis oder Weltkenntnis verstanden werden. Die letztere ist die pragmatische Anthropologie.

Die letztere untersucht nur ( $g$ in) so weit, was der Mensch ist, um daraus Regeln zu ziehen, was er aus sich machen oder andere brauchen kann. Nicht psychologie, welche eine Schulkenntnis ist. 
faculdades cognitivas no mundo, o que nos permite pensá-lo como o jogador e o produto dos diferentes jogos de que ele participa, no jogo social.

O terceiro texto a ser analisado é Die philosophischen Hauptvorlesungen Immanuel Kants: nach den neu aufgefundenen Kollegheften des Grafen Heinrich zu Dohna-Wundlacken, obra que trata dos cursos ministrados por Kant, entre 1791 e 1793. Em 1924, Kowalewski publicou essa obra, a qual compóe as obras completas de Kant organizadas pela Akademie, com o nome de Anthropologie Dohna-Wundlackende. A noção de antropologia pragmática presente nessa obra é igual à desenvolvida em Menschenkunde, pois nela o autor diferencia a antropologia pragmática da antropologia escolástica e indica que o homem deve ser investigado a partir do uso que ele realiza das suas faculdades cognitivas, no mundo. Sobre a diferença entre a antropologia escolástica e pragmática, Kant (Anth-Dohna ko 72-73) assim argumenta:

- escolasticamente (escolástica), especulativo, nesse ponto, ela [escolástica] conhece o homem, como ele é. Em sentido teórico, [a psicologia <doutrina da alma> é propriamente uma antropologia especulativa. Ela dirige-se ao interno.]

- popular (pragmático), na medida em que é útil para nós, a fim de que possamos realizar boas aplicaçóes, o que se sabe. [...] Toda doutrina prática é: 1. tecnicista, doutrina da arte e da habilidade, ou 2. Pragmática, utilizarmos o homem para meus propósitos, doutrina da prudência [...] A história pragmática torna a humanidade mais prudente (através das aplicaçôes), a teórica não. A antropologia pragmática fundamenta como alguém deve agir em comparação com a humanidade. ${ }^{12}$

Conforme Kant, a antropologia é composta por dois métodos distintos, o escolástico e o popular, que, nesse caso, são sinônimos de pragmático. A antropologia escolástica tematiza o homem do ponto de vista fisiológico e psicológico; essas ciências são excluídas por Kant, na elaboração do seu método antropológico. Ao contrário desse método, o pragmático investiga o

\footnotetext{
12 1. schulmäßig (scholastisch), spekulativ, insoweit sie uns den Menschen kennen lehrt, wie er ist. Dies ist die theoretische [die Psychologie <Seelenlehre> ist eine solche spekulative Anthropologie. Sie geht aufs Innere.]

2. populär (pragmatisch), insoweit sie uns nützlich ist, um von dem, was man weiß, gute Anwendungen machen zu können. [...] Alle praktische Lehre ist: 1. technisch, Lehre der Kunst und Geschicklichkeit, oder 2. pragmatisch, Lehre der Klugheit, Menschen zu meinen Absichten zu gebrauchen. [...] Pragmatische Geschichte macht den Menschen klüger (durch Anwendungen), theoretische nicht. Pragmatische Anthropologie gibt Maximen an die Hand, wie man gegen Menschen handeln soll.
} 
uso [Gebrauch] que realizamos das nossas faculdades cognitivas, no mundo, em especial o uso prático, o qual corresponde ao processo moralizador da humanidade. Como podemos perceber, nessa terceira versão dos cursos de Antropologia, Kant define a antropologia pragmática em contraposição à escolástica, na medida em que ele não examina o homem, nem do ponto de vista fisiológico e nem do psicológico. Nesse sentido, Kant ressalta que a sua investigação antropologia procurará determinar o que o homem pode fazer de si mesmo, como um ser social e moral.

Se alinharmos as três versões dos cursos de Antropologia de Kant, logo perceberemos três coisas: primeira - em todas as versões desses cursos, a ideia de antropologia é definida em contrapartida à antropologia escolástica; segunda - a antropologia faz parte do conhecimento do mundo, junto com a geografia física; terceira - a antropologia pragmática está submetida à doutrina da prudência, visto que o homem é investigado através dos efeitos que o uso das suas capacidades cognitivas produz, no mundo sensível, o que nos permite investigá-lo como o jogador e o produto dos diferentes jogos da vida. Por essa razão, a antropologia pragmática é sinônima de uma antropologia moral, nessas anotaçóes dos cursos de antropologia. Para ratificarmos o sentido atribuído ao conceito de antropologia pragmática, examinaremos, inicialmente, a crítica que Kant faz à antropologia escolástica como uma forma de pedantismo e, depois disso, examinaremos a ideia de prudência, nas aulas de Kant.

\section{A antropologia escolástica, o pedantismo}

Nas anotaçóes de Colleg, escritas aproximadamente entre 17731775, Kant argumenta que o conhecimento do mundo é formado pelo conhecimento do homem e pelo conhecimento da natureza. Entretanto, nessa obra, ele não afirma que o conhecimento do mundo é tratado pela Geografia física; diferentemente disso, ele apenas indica a complementaridade entre essas disciplinas, como partes integrantes do conhecimento do mundo. Nessa anotação dos cursos de Antropologia, o conhecimento do mundo é tido em contraposiçáo ao conhecimento escolar (Colleg, AA, 15:659). Essa oposição entre o conhecimento pedante e o conhecimento do mundo se repete, nas Aulas de Lógica. Nessa obra, Kant (Log, AA, 9:46) escreve:

[...] em relação às ciências, há duas degenerações do gosto predominante: o pedantismo [Pedanterie] e o cavalheiresco [Galanterie]. O pedantismo é praticado nas ciências escolares e limita dessa maneira o seu uso; o cavalheiresco é praticado apenas nos ambientes de reunióes e de companhia ou para o mundo e as limita, assim, no que concerne ao seu conteúdo. 
De acordo com Kant, o cientista pedante náo possui o conhecimento do mundo, por isso, ele náo sabe como transmitir popularmente o seu conhecimento aos homens. Dito de outro modo, o pedante é o enganador das fórmulas [Formalienklauber], dado que ele substitui a referência pela coerência lógica e abre mão do uso do conhecimento em favor das fórmulas lógicas. "Por isso, o pedantismo também pode ser caracterizado como uma minuciosidade rebuscada ou uma inútil exatidão de fórmulas" (Log, AA, 9:46). Assim, para Kant o pedante apenas se preocupa em transmitir a precisão lógica da fórmula, contudo, não demonstra o que é exigido à aplicação da mesma. Todavia, Kant adverte que não devemos ignorar, por isso, a exigência da perfeição lógica do conhecimento escolar, porque o exercício lógico não pode ser sacrificado em favor do cavalheirismo, pois as ciências não podem ser vistas como um tipo de passatempo.

A crítica kantiana ao pedante não significa que ele defenda a vulgarização do conhecimento, a qual ele chamou de conhecimento cavalheiresco [Galanterie]. Esse foi definido da seguinte maneira: “[...] assim como o cavalheirismo - semelhante à cortesã que busca o aplauso do gosto - nada mais é que uma popularidade afetada: o cavalheiro esforça-se exclusivamente para ganhar a simpatia do leitor e náo o molesta uma vez sequer com uma palavra difícil" ( $\log$, AA, 9:47). Diferente do pedante, o cavalheiro esforça-se em ganhar a simpatia do ouvinte, assim descartando o vocabulário específico das ciências em favor de uma linguagem simplicista, que significa a utilização de frases de efeito, mas vazia de conteúdo, e a especificidade da lógica em favor de generalizaçốes e exemplificaçôes.

Feitas essas observaçôes, agora é necessário definir o que Kant compreende por conhecimento popular, porque já definimos o que é o pedantismo e o cavalheirismo. Acerca do conhecimento popular, Kant (Log, AA, 9:47) assinala:

[...] com efeito, a verdadeira popularidade exige muito conhecimento prática do mundo e dos homens, conhecimento dos conceitos, do gosto e das inclinaçóes dos homens, o que sempre deve ser levado em conta na apresentação e mesmo já na escolha das expressóes convenientes e apropriadas à popularidade.

Conforme a citação, o conhecimento popular exige o conhecimento do homem e do mundo, que, apesar de Kant não citar nessa obra, nós podemos inferir que ele está se referindo às instruçóes de Geografia física e 
às de Antropologia. "As experiências da natureza e do homem formam juntas o Conhecimento do mundo. A antropologia nos ensina o conhecimento do homem, devemos o conhecimento da natureza à geografia física ou à descrição física da Terra" (PG, AA, 9:157). ${ }^{13}$ Na carta enviada a Herz (10:144), Kant afirma que as suas aulas de antropologia são constituídas por instruçôes preliminares do conhecimento do mundo; essas liçóes são compostas por conhecimentos das inclinaçôes e dos gostos dos seres humanos. Kant ( $\log$ 9:47) argumenta que, “[...] para evitar o pedantismo, são necessários vastos conhecimentos não só das próprias ciências, mas também do que é exigido para o seu uso". Isto significa que o conhecimento popular é definido pelo uso social viável de qualquer tipo de conhecimento.

Como exemplos de verdadeiro conhecimento popular, Kant indica a leitura dos poemas de Cicero, Horácio e Virgílio e a leitura de Hume e Shaftesbury, pois, nas obras desses autores, encontramos vastos exemplos de como o uso viável de um conhecimento pode defini-lo, mesmo que, em alguns momentos, apresente alguma incoerência formal - no entanto, isso não implica o cavalheirismo. Feita essa breve análise da crítica de Kant ao pedantismo, podemos afirmar que a metodologia popular empregada por Kant, em seus cursos de antropologia, trata da tematização da moral a partir do conhecimento empírico que temos da nossa natureza, entretanto, esse conhecimento não corresponde ao aspecto fisiológico ou psicológico dos seres humanos, mas do conhecimento das nossas inclinaçóes, disposiçôes e gostos. Por esse motivo, o efeito produzido pelo uso que o homem realiza das suas faculdades cognitivas no mundo é essencial, pois o uso nos permite compreendê-lo como o jogador do jogo social e como o produto desse jogo. A crítica kantiana ao pedantismo pode ser resumida na seguinte frase: as ciências pedantes não consideram que a humanidade é produto do seu próprio conhecimento.

\section{A IDEIA DE PRUdÊNCIA NAS ANOTAÇóES DOS CURSOS DE ANTROPOLOGIA}

De acordo com Brandt (1999, p. 117), o conceito de pragmático presente nessas versóes das aulas de antropologia aqui analisados foi retirado da obra Initia Philosophie practicae prima, de Baumgarten. Para demonstrar a influência de Baumgarten nas aulas de antropologia, citamos o Erläuterungen Kants zu "Baumgartens Initia Philosophie practicae prima", que são anotações

\footnotetext{
${ }^{13}$ Die Erfahrungen der Natur und des Menschen machen zusammen die Welterkenntnisse aus. Die Kenntnisse des Menschen lehrt uns die Anthropologie, die Kenntnisse der Natur verdanken wir der physischen Geographie oder Erdbeschreibung.
} 
de Kant acerca da obra do autor citado. Nessas anotaçóes, Kant sugere haver dois tipos de coação, a moral e a pragmática. A primeira trata da determinação da vontade segundo a lei moral, e a segunda ocupa-se das condiçóes de conciliação entre os arbítrios privados, sob a rege de um princípio moral. Esses dois modos de determinação do arbítrio foram retirados do $\$ 56$ da obra de Baumgarten. A fim de exemplificar esses dois tipos de coação, Kant (Erl, AA, 19:26) apresenta o seguinte esquema:

\begin{tabular}{c|c}
\multicolumn{2}{c}{ Coactio est vel practica vel physica } \\
vel \\
\hline Perstimulos & $\begin{array}{c}\text { per motiva [moralia] Regel } \\
\text { objektiver praktischer Zwang }\end{array}$ \\
\hline Erzwingung & vel \\
\hline \multicolumn{2}{|c}{} \\
\hline subiectiv & per moralia per pragmatica. \\
\hline
\end{tabular}

Segundo essas anotaçôes, existem dois tipos de coação, per stimulos e per motiva: esta se refere tanto à moral quanto à pragmática, enquanto aquela remete apenas à instintiva, a qual ocorre por uma imposiçáo da natureza. Desse modo, o autor classifica a coação per stimulos como subjetiva, porque ela enfoca uma determinação instintiva, dado ser uma ação necessariamente condicionada por um estímulo natural. Diferentemente da coaçâo per stimulos, a coação per motiva aborda a capacidade de os seres humanos agirem de acordo com a representação de um fim, que, nesse caso, pode ser um fim moral ou pragmático, pois o homem é um animal racional e dotado de liberdade.

A distinção feita por Kant da coação per stimulos e per motiva, em Collins, é igual à desenvolvida em suas anotaçôes da obra de Baumgarten. Em ambas as obras, Kant argumenta que toda coação prática não é subjetiva, porém, é objetiva, porque o motivo da ação é compatível com a ideia de liberdade positiva. Dessa maneira, a coação prática trata da eleição de um fim determinante da vontade, que pode ser classificado como pragmático ou moral. Acerca do primeiro tipo, Kant (V-Anth/Collins 27:258) escreve o seguinte:

[...] todos os motivos pragmáticos são meramente condicionados, na medida em que as açóes são meros meios para a felicidade, por isso não possuem, neste caso, um fundamento para a ação em si, mas o que significam. Em razão disso, todos os imperativos pragmáticos são necessariamente hipotéticos e não absolutos. Mas, os imperativos morais 
são necessariamente absolutos e expressam uma bonitas absoluta, da mesma forma que os imperativos hipotéticos expressam uma bonitas hypothetica. Portanto, com o fundamento na prudência, a veracidade pode ser imediatamente boa - no comércio - é táo boa quanto o dinheiro - mas considerada no sentido absoluto, e para todos os propósitos, e a mentira não é verdadeira em si ${ }^{14}$ (V-Anth/Collins 27:258).

Todo motivo pragmático é condicionado, já que os motivos são tidos como os meios necessários para se alcançar a felicidade. Por essa razão, dos motivos pragmáticos apenas derivamos imperativos hipotéticos e nunca categóricos, mas, segundo Kant, esse tipo de imperativo é possível, mediante uma coação por motivo e nunca por estímulo, mesmo que o imperativo não seja categórico. Ainda conforme as Liçóes de Collins (V-Anth/Collins 27:246),

[...] prudence is readiness in the use of means to the universal end of man, namely happiness, and thus here the end is already determined, which is not the case with skill. For the rule of prudence there are two requirements: to determine the end itself, and then the use of means to this end.

Nessa citação, Kant distingue os fins da humanidade, segundo a felicidade e segundo a habilidade; o último não exige a determinação de um fim geral prévio, o que ocorre no caso do primeiro.

Nas Liçôes de Collins, o conceito de prudência é definido como o emprego de respectivo meio para a realização de um fim, que nomeadamente é a felicidade. Para validar essa designação de prudência, o autor destacou dois requisitos: primeiro requisito, a capacidade do ser humano em determinar um fim para si mesmo; segundo requisito, a capacidade do agente em eleger os meios para a realização desse fim. Assim, nessa lição de ética, a prudência é a habilidade do agente moral em escolher os meios necessários para se alcançar a felicidade.

Acerca do adjetivo pragmático, Kant (GMS, AA, 4:417) escreve, em uma nota de rodapé da Fundamentação da metafísica dos costumes:

\footnotetext{
${ }^{14}$ all pragmatic motives are merely conditioned, insofar as the actions are means to happiness, so here there is no ground for the action itself, but merely qua means. Hence all imperativi pragmatici hypothetice necessitant e non absolute. But imperativi morales necessitant absolute and express a bonitas absoluta, just as the imperativi pragmatici express a bonitas hypothetica. So on grounds of prudence, truthfulness can be immediately good - in commerce, for exemple, it is as good as ready cash - but regarded in the absolute sense, to be truthful is good in itself, and for every purpose, and untruth is in itself vile.
} 
[...] parece-me que a verdadeira significação da palavra pragmática se pode assim determinar da maneira mais exata. Chamam-se pragmáticas as sançôes que decorrem propriamente náo do direito dos Etados como leis necessárias, mas da prevençâo pelo bem-estar geral. A história é escrita pragmáticamente quando nos torna prudentes, quer dizer, quando ensina o mundo atual a maneira de assegurar a sua vantagem melhor ou pelo menos táo bem como o mundo das geraçóes passadas. ${ }^{15}$

Nessa citação, o autor determina que o conceito de pragmática ocupase da prevenção do bem-estar em geral, o que, em tese, está em acordo com as versôes dos cursos de Antropologia, pois trata da capacidade dos seres humanos em agirem conforme a ideia de felicidade. Ainda na obra acima citada, Kant (GMS, AA, 4:417) declara, sobre a ideia de prudência:

[...] a palavra prudência (Klugheit) é tomada em sentido duplo: ou pode designar a prudência do mundo (Weltklugheit) nas relaçóes com o mundo, ou a prudência privada (Privatiklugheit). A primeira é a habilidade (Geschicklichkeit) de uma pessoa no exercício de influência sobre outras para utilizá-las para as suas intenções. A segunda e a sagacidade (Einsicht) em reunir todas estas intençōes para alcançar uma vantagem pessoal durável. A última é propriamente aquela sobre que reverte mesmo o valor da primeira, e quem é prudente no primeiro sentido, mas que não é no segundo, desse se poderá antes dizer: é esperto e manhoso, mas em suma é imprudente.

O primeiro sentido da palavra prudência trata da nossa capacidade de lidar com outrem, a fim de juntos realizarmos um fim comum. O segundo sentido diz respeito ao caráter do ser racional finito, pois, nessa asserção, prudência significa a capacidade de alcançar, mediante as próprias intençôes, um bem durável, que nesse caso é a virtude. A vantagem durável é a participação do reino dos fins, ou seja, ter a si mesmo como outrem simultaneamente como fim e não como meio. Kant definiu o reino dos fins como "a ligação sistemática de vários seres racionais por meios de leis comuns” (GMS, AA, 7:74175), que remete à relação entre os homens, intermediada pela lei moral. Isso significa que todos os seres humanos estão submetidos a fins, que são morais ou náo, contudo, como participante do reino dos fins, todos os homens

\footnotetext{
${ }^{15}$ Mich deucht, die eigentliche Bedeutung des Worts pragmatisch könne so am genauesten bestimmt werden. Denn pragmatisch werden die Sanktionen genannt, welche eigentlich nicht aus dem Rechte der Staaten als notwendige Gesetze, sondern aus der Vorsorge für die allgemeine Wohlfahrt fließen. Pragmatisch ist eine Geschichte abgefasst, wenn sie klug macht, d.i. die Welt belehrt, wie sie ihren Vorteil besser, oder wenigstens eben so gut als die Vorwelt besorgen könne.
} 
estão obrigados a tratar a si mesmos e outrem nunca como meio, mas sempre simultaneamente como um fim em si, logo, ninguém pode ser um meio para minha felicidade, o que me permite alcançá-la apenas socialmente.

O sentido do termo prudência privada, desenvolvido na Fundamentação da Metafísica dos Costumes, é igual ao sentido de prudência apresentado na Reflexão 1518, sob a condição de que a prudência privada é a capacidade do agente moral em definir o verdadeiro valor moral das coisas. Na Reflexão 1518 , Kant $(R x, \mathrm{AA}, 15: 873)$ define a prudência do seguinte modo: “[...] por volta dos 40 anos forma-se primeiro a autêntica forma de pensar. ( Também prudência, isto é, a capacidade de diferenciar o verdadeiro interesse da aparência.) ( $\mathrm{s}$ de avaliar o valor das coisas.)". Esse trecho foi escrito entre 1783 e 1784, provavelmente ao mesmo tempo em que Kant revisava o texto da Fundamentação da Metafísica dos costumes para sua publicação, que aconteceu em 1785. Naquela reflexão antropológica, Kant definiu a prudência como a capacidade de avaliar o verdadeiro valor das coisas, o que possibilita ao homem distinguir o verdadeiro interesse moral do falso interesse.

A aparência moral pode ser concebida como a falsidade do caráter ou como os defeitos do caráter (fehlerhafte Charakter). Para Kant (Rx, AA, 15:872), "[...] a falsidade é o verdadeiro mal do caráter, pois a falsidade contém os princípios do mal. Não misantropia ou também intolerância, inveja, ingratidão, satisfação maliciosa)". Dito de outro modo, por exemplo, a misantropia, para o autor, faz parte dos defeitos do caráter, porque sua causa pode ser a incapacidade de um jovem em determinar o verdadeiro valor moral das coisas. Diferente dos defeitos do caráter, a falsidade do caráter não concerne a uma incapacidade do uso pleno da razão, pelo contrário, a falsidade se refere à determinação do verdadeiro valor moral das coisas. Entretanto, Kant adverte que aqueles que somente tiverem a prudência do mundo não poderão ser chamados de prudentes, mas deveráo ser chamados de imprudentes, todavia, esse tipo de prudência é tido como uma habilidade necessária para a vida social. Assim, a prudência do mundo trata da habilidade dos homens em buscar o bem-estar, a qual pode ser convertida em prudência privada, que é a aquisição de um bem durável. Contudo, é importante observar que, de acordo com a doutrina moral kantiana, não podemos alcançar a felicidade individualmente, mas apenas socialmente.

Em linhas gerais, a definição de prudência desenvolvida nas obras aqui citadas está em acordo com a tese defendida por Louden, pois, segundo o pesquisador, a antropologia pragmática investiga os efeitos fenomênicos da 
liberdade humana no mundo empírico, os quais se referem, por um lado, aos obstáculos que impedem a realização da lei moral pelos seres humanos e, por outro lado, ao modo como os seres humanos influenciam uns aos outros, na realização de diversos fins, que é a lei moral e a felicidade.

Apresentadas as observaçóes acima, podemos argumentar, por conseguinte, que o sentido do termo prudência, presente em Menschenkunde e em Anthropologie-Dohna, também está evidente na Fundamentação da Metafísica dos Costumes $^{16}$, na medida em que a prudência, em seu sentido pragmático, indica a habilidade do homem em agir direcionada a fins, que é a prevenção do bem-estar (felicidade) ou o aperfeiçoamento do próprio caráter. Porém, no caso da antropologia pragmática, a felicidade somente é possível socialmente e não individualmente. Asseverar que o homem possui a capacidade de operar de acordo com fins, em sentido pragmático, implica dizer que: primeiro, ele possui a habilidade de utilizar os outros segundo suas intençôes (prudência privada); segundo, ele pode converter essa capacidade em um bem durável, ao avaliar o verdadeiro valor moral das coisas, o que foi chamado por Kant de sabedoria (Weisheit), nas suas versóes dos cursos de antropologia.

\footnotetext{
${ }^{16}$ Se nós compararmos a noção de prudência do mundo com a noção de prudência desenvolvida em Menschenkunde e Anthropologie-Dohna, podemos afirmar que ambas possuem o mesmo significado, pois o próprio Kant, na Fundamentaçâo da Metafísica dos Costumes, advertiu que o conceito de prudência privada corresponde à habilidade de uma pessoa em exercer influência sobre outras e utilizá-las a favor das suas intenções. Ainda referente à ideia de prudência, Kant escreveu o seguinte, na Antropologia de um ponto de vista pragmático, publicada em 1798: "A idade em que o homem chega ao pleno uso de sua razão poderá ser fixada, em vista de sua habilidade (Geschicklichkeit) (a faculdade de atuar com arte em qualquer propósito), por volta dos vintes anos; em vista da prudência (Klugheit) (de utilizar outros homens para os seus fins), dos quarentas; finalmente, em vista da sabedoria (Weisheit) por volta dos sessenta; nesta última época, porém, ela é mais negativa, para compreender todas as tolices das duas primeiras, quando se poderia viver bem, e mesmo entấo esse juízo ainda é raro, pois que a inclinação pela se torna tanto mais forte, quanto menos valor ela tem, tanto na açáo quanto no prazer." (Anth 7:201) Essa citação diz respeito à capacidade do homem em fazer o uso pleno da sua razão, que, conforme o autor, está associada com a terceira faixa etária apresentada. Além disso, também podemos expressar a capacidade do uso pleno da razão, a partir de três máximas: " $1^{\circ}$ ) pensar por si mesmo; $2^{\circ}$ ) colocar-se no lugar do outro (na comunicação com seres humanos); $3^{\circ}$ ) pensar sempre em concordância consigo mesmo." (Anth 7:200) Em outras palavras, essas máximas são coordenadas que ajudariam o homem a retirar de si a sabedoria, pois é impossível infundir sabedoria nele. Tendo em vista esse panorama, Kant identificou cada uma das máximas como um tipo de exercício para atingir o uso pleno da razão, mas que tal uso somente será possível a partir dos 40 anos. Nessa passagem do texto de 1798, o autor também definiu a habilidade como a capacidade de usar a razão direcionada a fins, a prudência como a capacidade de ser humano em utilizar outro em favor dos seus propósitos, e a sabedoria como a capacidade de tolerar as tolices dos outros. Assim, podemos asseverar que o significado da palavra prudência, presente nessa obra, inclui o sentido tanto da prudência do mundo quanto o sentido da prudência privada, desenvolvidos na Fundamentação da Metafísica dos Costumes.
} 
Ainda acerca da doutrina da prudência, Kant (KrV A800\B828) escreve:

[...] prático é tudo aquilo que é possível pela liberdade. Mas, se as condiçóes de exercício do nosso livre arbítrio são empíricas, a razão só pode ter, nesse caso, um uso regulador e apenas pode servir para efetuar a unidade de leis empíricas; assim, na doutrina da prudência, a unificação de todos os fins, dados pelas nossas inclinaçōes num fim único, a felicidade, e a concordância dos meios para alcançar [...] constituem toda a obra da razão que, para esse efeito, não pode fornecer outra coisa senão leis pragmáticas da nossa livre conduta, próprias para nos alcançarem os fins recomendados pelos sentidos, mas de modo nenhum leis puras complementados pelos sentidos, mas de modo nenhum leis puras completamente determinadas a priori.

Nessa obra, a ideia de prudência está associada às condições empíricas do exercício do nosso livre arbítrio, pois trata da unificação de todos os fins dados pelas nossas inclinaçôes em um único fim, que é a felicidade. Entretanto, esses fins não constituem leis práticas, pois eles focalizam os meios para alcançar e, por isso, são tidos como leis pragmáticas. Nesse caso, a doutrina da prudência faria parte do que Louden (2011) chama de ética aplicada, porque a antropologia pragmática aborda as condiçóes empíricas da realização de certo fim, que é a felicidade. Dito isso, nas palavras do pesquisador, "a antropologia pragmática estuda os efeitos fenomênicos da liberdade humana no mundo empírico, não a suposta origem não empírica delas" (LOUDEN, 2011.p. 81). Isso significa que a antropologia investiga as condiçóes empíricas do exercício do nosso livro arbítrio, já que examina os efeitos fenomênicos da liberdade humana, no mundo empírico. Por essa razáo, a antropologia pragmática pode ser incluída na segunda parte da moral kantiana, porque ela lida apenas com as leis pragmáticas que tratam da união das condições empíricas do livre arbítrio, que, nesse caso, é a felicidade.

\section{CONSIDERAÇốES FINAIS}

Nas diferentes versóes dos cursos de antropologia aqui consultados, Collegentwürfe, Menschenkunde e Anthropologie Dohna-Wundlackende, a antropologia pragmática investiga o que o homem pode fazer de si mesmo como um ser racional, todavia, esse exame ocorre mediante os efeitos produzidos pelo uso que ele faz da sua capacidade racional no mundo. Por essa 
razão, nessas anotaçóes, o homem é tido como um jogador, na medida em que determina as regras dos jogos, porque ele não é um mero produto da natureza, mas sim da sua capacidade racional. Nesse sentido, propomos diferenciar a antropologia pragmática da escolástica: esta considera que o homem é um mero produto da natureza, enquanto aquela o concebe como um produto do seu próprio conhecimento.

Além disso, indicamos que a metodologia popular empregada por Kant, em seus cursos de antropologia, se ocupa da investigação do homem a partir do conhecimento empírico que temos da nossa natureza, o que não significa que examinamos o ser humano do ponto de vista da fisiologia ou psicologia. Ao invés disso, investigamos o que é o homem, através do uso que ele faz do seu conhecimento no mundo. Em razáo disso, defendemos que a antropologia pragmática ,nas três versóes dos cursos de antropologia, corresponde a uma antropologia moral, entendida como uma doutrina da prudência. Ademais, a noção de prudência presente nas versôes de antropologia consultadas é retirada da obra de Baumgarten, Initia Philosophie practicae prima, pois a doutrina da prudência trata das condições empíricas da conciliação entre os arbítrios dos seres humanos, visto que nós nos unimos, a fim de nos educarmos, moralizarmos e civilizarmos. Em razão disso, a antropologia pragmática é definida nessas obras como o estudo do que o homem é capaz de fazer de si mesmo, do ponto de vista educacional, moral e civilizatório. Por fim, defendemos que a antropologia pragmática deve ser compreendida como uma doutrina da prudência.

CONCEIÇÃO, J. V. C. The pragmatic anthropology as a doctrine of prudence in the versions of the courses of anthropology from Kant. Trans/form/ação, Marília, v. 43, n. 2, p. 77-98, Abr./Jun., 2020.

ABSTRACT: This article aims to evidence that the idea of pragmatic anthropology developed in the versions of the courses of anthropology that are Collegentwürfe, Menschenkunde and Anthropologie Dohna-Wundlackende, occupies of a moral definition, because it is subordinated to the doctrine of prudence. This doctrine is understood as the capacity from the human beings to influence each other according to certain goals, the ones that should be useful in social life. Besides that, we will delimit that the meaning of the pragmatic adjective present in these versions of the courses of anthropology was withdrawn from the work Initia Philosophiae practicae prima from Baumgarten, because in the notes of Kant about this work the pragmatic motives will always determine private laws of the will, the ones 
who may, a priori, represent a moral interest and, a posteriori, the accomplishment of a desired end by its finite rational being. By this reason, we defend to have in the quoted Kantian works a synonymy between the notion of pragmatic anthropology and the doctrine of prudence.

KeYwords: Pragmatic anthropology. Doctrine of prudence. Moral applied. Impure Ethics. Baumgarten.

\section{REFERÊNCIAS}

BRANDT, R. Kommentar zu Kants Anthropologie. Hamburg: Felix Meiner Verlag $\mathrm{GmbH}, 1999$.

CONCEIÇÃO, J.V.C. Antropologia fisiológica e a antropologia pragmática: a ideia de uma natureza humana em Kant. Synesis, v. 8, n. 2, p. 118-148, ago/dez. 2016.

FRIERSON, P. What is the human being? London and New York: Routledge, 2013. FOUCAULT, M. Gênese e estrutura da antropologia de Kant. Editora Vozes: São Paulo, 2011.

KANT, I. Menschenkunde: oder philosophische Anthropologie. Leipzig, 1831.

LOPARIC, Z. A semântica transcendental de Kant. Campinas: UNICAMP, Centro de Lógica, Epistemologia e História da Ciência, 2005.

LOUDEN, R. Kant's Impure Ethics. New York: Oxford University Press, 2000.

LOUDEN, R. Kant's human being: essays on his theory of human nature. New York: Oxford University Press, 2011.

LOUDEN, R. The second part of morals. In JACOBS, B, KAIN, P. Essays on Kant's Anthropology. New York: Cambridge University Press, 2003.

PEREZ, D. A antropologia pragmática como parte da razão prática em sentido kantiano. Manuscrito - Revista Internacional de Filosofia, v. 32, n. 2, p. 357-397, 2009.

PEREZ, D. O significado de natureza humana em Kant. Kant e-Prints, v. 5, n. 1, p. 75-87, 2010.

PLATNER, E. Anthropologie für Arzte und Weltweise. Leipzig: Georg Holms Verlag, 1772.

KANT, I. Immanuel Kant's Menschenkunde: oder philosophische Anthropologie. In STARK, F. (Org.) Immanuel Kant's Menschenkunde: oder philosophische Anthropologie Leipzig: Nabu Press, 1831. 
CONCEIÇĀO, J. V. C.

\section{Siglas das obras de KanT}

Kant im Kontext III (Komplettausgabe 2013). (C) Karsten Worm - InfoSoftWare 2013.

$\mathrm{KrV} \quad$ Kritik der reinen Vernunft (zu zitieren nach Originalpaginierung $\mathrm{A} / \mathrm{B})$

GMS Grundlegung zur Metaphysik der Sitten (AA 04)

Anth Anthropologie in pragmatischer Hinsicht (AA 07)

$\mathrm{Br} \quad$ Briefe (AA 10-13)

PG Physische Geographie (AA 09)

Refl Reflexion (AA 14-19)

Colleg Collegentwürfe aus den 80er Jahren.

V-Anth/Col. Vorlesungen Wintersemester 1772/1773 Collins (AA 25)

V-Anth/Fr. Vorlesungen Wintersemester 1775/1776 Friedländer (AA 25)

V-Anth/Men Vorlesungen Wintersemester 1781/1782 Menschenkunde, Petersburg (AA 25)

V-Mo/Collins Moralphilosophie Collins (AA 27)

Anth-Dohna Vorlesungen über Anthropologie: Anthropologie Dohna Wundlaken

Erl Erläuterungen Kants zu „Baumgartens Initia Philosphie practicae prima(AA 19) 